\title{
UNUSUAL SCROTAL SWELLING IN A NEWBORN: A CASE OF MECONIUM PERIORCHITIS
}

\author{
Duminda $\mathrm{WD}^{1}$, Pathirana $\mathrm{KG}^{2}$, Fernando $\mathrm{MUJ}^{2}$, Samarasinghe RANKK ${ }^{2}$,Mallikaarachchi $\mathrm{AJ}^{2}$ \\ ${ }^{1}$ Department of Radiology, National Hospital of Sri Lanka \\ ${ }^{2}$ Department of Radiology, Lady Ridgeway Hospital for Children, Colombo-08, Sri Lanka
}

DOI: http://doi.org/10.4038/sljr.v3i1.25

Keywords: Meconiumperiorchitis, Scrotal mass or swelling

\section{Introduction}

Meconium is a greenish colour viscous intestinal content in the distal small bowel seen in late stages of fetal life. Meconium contains swallowed amniotic fluid, bile salts, bile pigments, mucin, intestinal enzymes, squamous cells, lanugo hair etc. Meconium peritonitis occurs following a bowel perforation during late fetal life or in early postnatal period allowing meconium to enter the peritoneal cavity. This may be associated with volvulus, bowel atresia, or mesenteric vascular insufficiency ${ }^{1}$. Passage of meconium in to the scrotal sac is one of the extra-abdominal complication of meconium peritonitis $^{1,2}$.

Meconium periorchitis (MPO) is a rare condition associated with meconium peritonitis. Patients present with a soft hydrocoele at birth but it later becomes hard as the meconium calcifies. There is a tendency of spontaneous resolution of the mass and the calcifications without compromising the testes ${ }^{3,4}$. The clinical presentation may mimic testicular tumour ${ }^{5}$.Ultrasonography of the scrotum will show a heterogeneous mass with calcifications ${ }^{4}$.

\section{Case Report}

An eight day old baby boy presented to a local hospital with bilious vomiting and a Right scrotal swelling which was firm on palpation. Ultrasonography confirmed a right scrotal mass and the patient was transferred to a paediatric tertiary care hospital with the suspicion of a testicular teratoma, for further management.

Ultrasonography performed at the tertiary care hospital reveled a right extra-testicular heterogeneous mass with calcified foci within it. The right testis was found to be normal (Fig1). Left hemiscrotum was also normal. Abdominal ultrasonography revealed

Corresponding Author: Duminda WD <dumindawithanage@gmail.com>

https://orcid.org/0000-0002-9958-9534

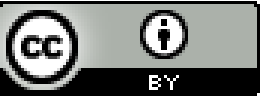

This is an open-access article distributed under the terms of the Creative Commons Attribution 4.0 International License, which permits unrestricted use, distribution and reproduction in any medium provided the original author and source are credited. 
a heterogeneously echogenic area in the hepato-renal pouch (Fig 2), which was apparent on abdominal X-ray as calcifications (Fig 3). The diagnosis of MPO was made based on radiographic and sonographic findings.

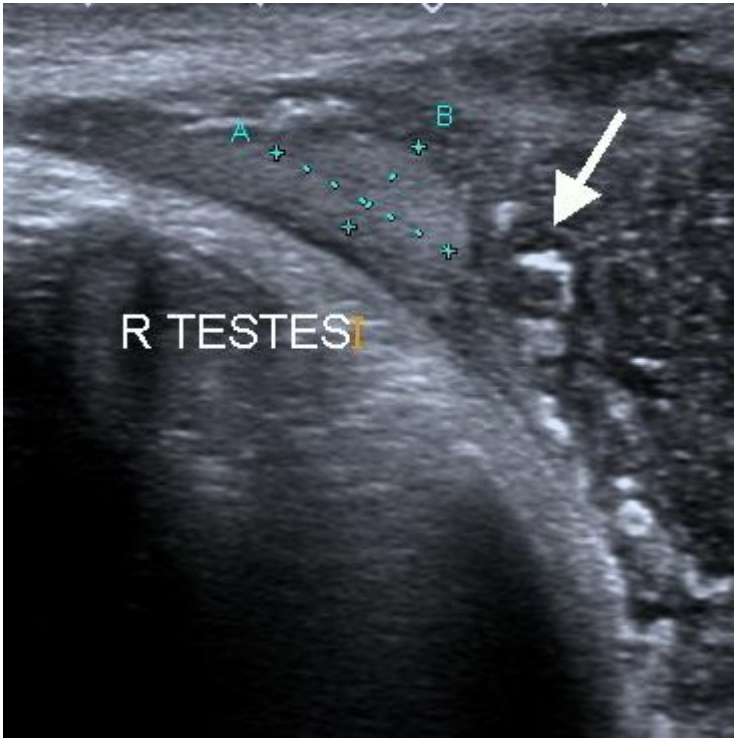

Figure 1: Ultrasound of the right testis demonstrating normal echogenicity of the right testis with peritesticular calcifications.

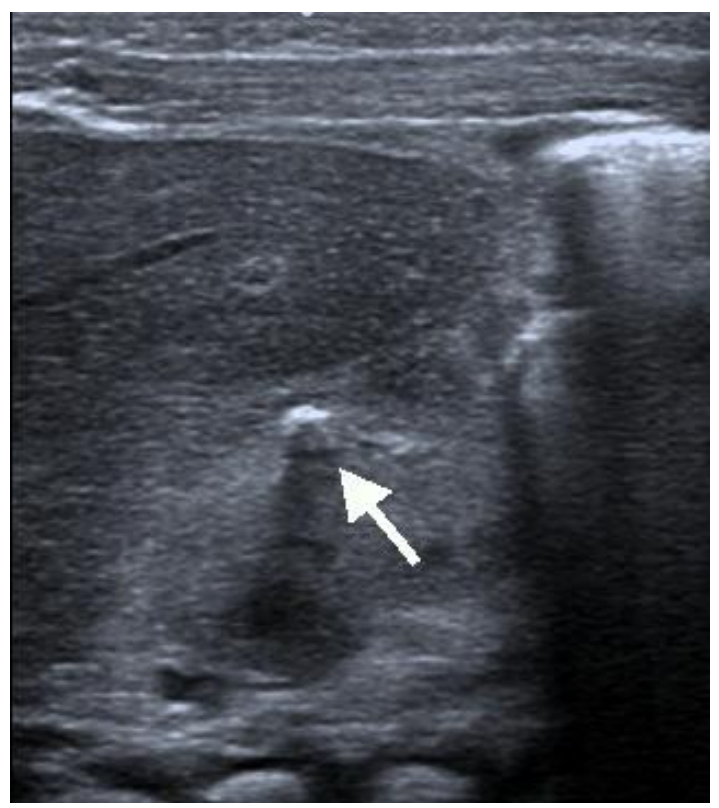

Figure 2: Ultrasound scan of the abdomen demonstrating heterogeneously echogenic area in the hepato-renal pouch due to calcific foci.

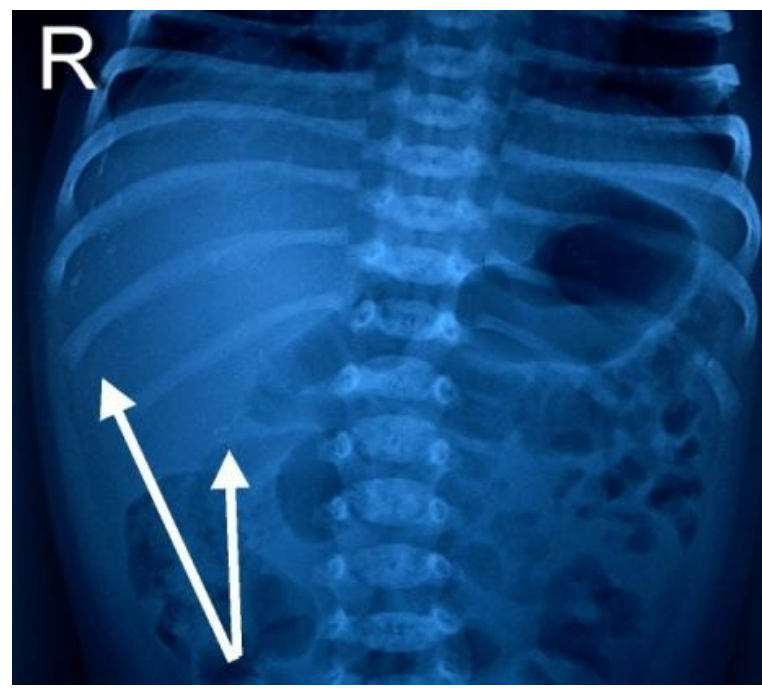

Figure 3: Abdominal $\mathrm{X}$ ray demonstrating calcifications in the abdominal cavity(Arrows)

The patient underwent laparotomy due to persistent bilious vomiting and abdominal distension even though there was no definitive evidence of intestinal obstruction on above radiological investigations. Perforated small bowel loop with meconium in the peritoneal cavity and secondary intestinal obstruction were identified at laparotomy supportive of MPO.

\section{Discussion}

Meconium periorchitis is an uncommon condition presenting in the early neonatal period with a scrotal mass. Meconium in the peritoneal cavity following a bowel perforation passing through the patent processus vaginalis in a male patient is the mechanism behind this condition. Many of the infant boys with MPO are reported to have had reducible hydrocoeles at birth, often bilateral. However, approximately $25 \%$ of patients do not have any scrotal abnormality at birth ${ }^{3}$. Our patient had only unilateral scrotal swelling, which was not reducible. 
The condition is seldom diagnosed accurately during antenatal period with the ultrasonographic diagnoses varying from normal to haematoma or hydrocoele ${ }^{6}$. Nevertheless, postnatal ultrasonography of the scrotum may show a well-defined scrotal mass enveloping the testis and epididymis with echogenic shadows representing foci of calcification. Abdominal radiographs may demonstrate peritoneal calcifications as in our case. However, abdominal calcifications are absent in approximately $10 \%$ of reported cases $^{3}$.

In literature most cases of MPO have been confirmed surgically, but in a case with typical sonographic findings and abdominal calcifications on radiography, surgery could be avoided ${ }^{7}$.

Our patient underwent surgery due to persisting bilious vomiting with abdominal distension.

\section{Take home message:}

In neonates with scrotal swelling MPO should be considered as a differential diagnosis and one should be vigilant of characteristic calcific foci on abdominal radiographs which are suggestive of this condition.

\section{References}

1. Boccon-Gibod L, Roucayrol AM. Meconium periorchitis. Pediatr Pathol 1992;12:851-6.

2. Patton WL, Lutz AM, Willmann J, Callen P, Barkovich AJ, Gooding CA. System spread of meconium peritonitis. Pediatr Radiol 1998;28: 714-6.

3. Varkonyi I, Fliegel C, Rösslein R, et al. Meconium periorchitis: case report and literature review. Eur J Pediatr Surg. 2000 Dec;10(6):404-7.

4. Acosta P,Gambina F, Perelli L, et al. Meconium periorchitis: A case report. Arch Argent Pediatr. 2015 Dec 1; 113 (6): e330-2.

5. Barry Chang, Lane S Palmer. Meconium periorchitis presenting as scrotal masses. Urology 2002; 59: 296.

6. Regev RH, Markovich O, Arnon S, et al. Meconium periorchitis: intrauterine diagnosis and neonatal outcome: case reports and review of the literature.J Perinatol. 2009 Aug;29(8):585-7.

7. Thomas E. Herman, Marilyn J. Siegel. Perinatal/Neonatal Case Presentation; Meconium Periorchitis. Journal of Perinatology. 2004; 24, 53-55. 